\title{
REGRESSION ANALYSIS OF NATIONAL ELECTIONS IN JAPAN USING SOCIAL LISTENING
}

\author{
Hisaki Goto ${ }^{1}$ and Yukiko Goto ${ }^{2}$ \\ ${ }^{I}$ Nagoya Gakuin University, Nagoya, Japan \\ ${ }^{2}$ Enconnect Inc., Fukuoka, Japan
}

\begin{abstract}
In this study, results predictions on Japan's national elections are made by analyzing data obtained through social listening. The amount of information sent by end users has become enormous as expressed as "information explosion", and social media is a representative source of such information. Social listening on national elections after the internet campaign became available in 2013 was conducted in this study, and a new finding in results predictions that could replace a conventional prediction method, especially in the proportional representation system, was made.
\end{abstract}

\section{KEYWORDS}

Social Listening, Internet Election, Internet Election Campaign, Election Results Predictions, Regression Analysis

\section{INTRODUCTION}

A conventional method used for election results predictions in Japan is RDD (Random Digit Dialing), in which media randomly call landline telephones to gather statistics. However since people nowadays have mobile phones and those especially under 40 years of age choose not to own landline phones, the RDD method has become less effective for predictions. Although research methods using mobile phones have been sought, mobile phones in Japan do not have area codes which make it impossible to obtain regional information through mobile phones.

As an alternate method of the RDD social listening has drawn attention. Through social listening, which tracks conversations about specific topics, keywords, phrases, products, etc. posted in social media, it is possible to collect massive data that was not available previously, and with that prospect social listening plays an important role in society. For example, under the conventional method, marketing research is conducted by gathering information at the scene or by survey using a certain number of samples for product development, marketing and management. In contrast, social listening makes it possible for companies to listen to numerous opinions from consumers and society through SNS (Social Network Service); as a result consumers and society can be put in the center for product development, marketing and management.

SNS such as Facebook and Twitter is quite actively used in Japan. Especially Twitter is exceedingly popular enough for Twitter Inc. to portray Japan's love of Twitter as "insane". This research is to look into the effectiveness of SNS as a tool for election results predictions by collecting data through social media after the ban on Internet campaigns was lifted in Japan in 2013. It is found that results predictions of Japan's national elections using social media is possible for nationwide proportional representation.

\section{BACKGROUND OF STUDY}

In this chapter social listening and Internet elections in Japan are discussed as the background of the study. 


\subsection{Internet Election Campaigns in Japan}

Election campaigns using the Internet had not been available in Japan due to the Public Offices Election Laws which regulate various campaign activities such as door-to-door canvassing, pre-election campaigns and distribution of documents to protect the fairness and equality of elections. Among them is the prohibition of distribution of documents and drawings (such as post cards, placards or flyers), and the Supreme Court decided that the contents displayed on computer screens or cell phones are also considered documents or drawings; therefore, election campaigns using the Internet had not been available. However election campaigns which utilize the IT era had been discussed, and "The Act for Amending Part of the Public Offices Election Law related to Permission for Internet Election Campaigns" was passed in 2013, through which election campaigns using social media became available. The Japanese national elections have two types; the Lower House elections and the Upper House elections. The Lower House election consists of 289 single-member districts and 11 proportional representation electoral districts for 176 seats. The Upper House election consists of 47 districts for 73 seats and 48 seats by proportional representation on the national level.

\subsection{Social Media in Japan}

A social network service that holds the largest number of accounts in Japan (total population 126,937,000 as of November 1, 2016) is LINE with 68 million users, followed by Twitter and Facebook with 40 million and 27 million users respectively. However, LINE could be called a closed social media because LINE is to exchange messages between friends and family members, and the size of the network is quite small compared to Twitter. Thus, Twitter and Facebook are appropriate for this study. Twitter Inc. portrays Japan's love of Twitter as "insane". The world record for the number of tweets per minute is 618,725 tweets right after the match between Argentina and Germany during the 2014 Soccer World Cup, and the world record for the number of tweets per second is 143,199 during the Japanese animated adventure film "Laputa: Castle in the Sky" broadcast on August in 2013. In addition, Japan dominates high ranking positions in the number of tweets per second.

\section{LITERATURE REVIEW}

Analysis of elections using social media have been conducted in many countries such as by Tumasjan, A. et al. (2010) and Jungherr, A. et al. (2012) that focused on the number of tweets. Tumasjan, A. et al. (2010) and Jungherr, A. et al. (2012) both analyzed a German Federal election using 100,000 tweets, and they found contradictory results. This may have been caused by an insufficient number of twitter users in Germany as Doerner S. (2014) indicated. The research by Daniel G. et al. (2011) and Jessica C. et al. (2011) using emotion analysis from 240,000 data found contradictory results as well.

In Japan Nasuno et al. (2013 and 2014) and Yoshimi (2016) published studies focusing on social media to analyze Japanese elections after the ban on Internet campaigning was lifted. Nasuno et al. (2013 and 2014) analyzed the 23rd Upper House regular election using 42,645 tweets by 287 candidates and 368,694 of retweets of them. Also Yoshimi (2016) targeted 30,941 tweets posted on their official accounts by 537 candidates running from five major political parties in the 47th Lower House general election. The above three studies only show a tendency due to the scarce amount of data.

On the other hand, this study takes advantage of the Japanese insane love of Twitter, through which anonymous online support groups are created. As Goto (2015) found the predictions in small constituencies at national elections were not possible due to the scarce number of postings. Our research found that for other candidates several hundred to one thousand tweets is the line to win, but that data shows tendencies only. The same thing can be said for candidates who rely on organized votes 1. For example, Yoshifumi

\footnotetext{
${ }^{1}$ Votes cast for specific candidates or parties by various groups or organizations. Large units of professional office workers (such as self-defense army or police), industry groups, labor unions, interest groups, religious groups are applied to those groups or organizations. A political party Komei was founded based on Sokagakkai, a Buddhist religious corporation, to achieve moderate political influence and wins seats by organized votes.
} 
Takushoku earned the largest number of votes of 429,002 at the 23rd Upper House general election in spite of the fact that the number of postings containing his name was only 8 . He is a former head of the national association of postmasters and received organized votes from postal businesses. Thus, with this research method it is difficult to analyze parties or individual candidates in small constituencies or who rely on organized votes. However, analysis by party name in the proportional representation system is effective. For this study 956,268 tweets and Facebook postings that contained political party names for the $23^{\text {rd }}$ Upper House regular election were collected. Furthermore, 1,287,982 tweets for the $47^{\text {th }}$ Lower House general election and 1,777,724 tweets during the $24^{\text {th }}$ Upper House general election were collected. With this overwhelmingly large volume of data compared to other research performed in Japan or other countries this study is distinguished from others.

\section{RESEARCH METHOD}

A regression analysis using data collected via social listening was performed for this study. In this chapter the methods for social listening and analysis are discussed.

\subsection{Methods for Social Listening}

Social listening data regarding Japanese national elections are collected through Yahoo! Japan real-time search. The Public Offices Election Law allows an election campaign only between a candidate's registration on the date of a public announcement and a day before a voting date. Campaigning in another period such as pre-election campaign before a candidate registration is prohibited. Therefore, the period for social listening is between the date of public announcement and a day before a voting date.

The media such as press and TV station conduct a sample survey using RDD during election campaigns to predict the election results. Through social listening more precise information can be collected by taking advantage of information generated via Twitter in a spontaneous manner during the same period.

As Goto (2015) previously noted, the number of tweets by candidates name in small constituencies were too scarce to use for the analysis of elections. Also the same can be said of candidates who rely on organized votes. Therefore, social listening was conducted by party names in the proportional representation system using Yahoo! Japan Real-time Search. Some parties cannot be identifiable; for example, although at the 23rd Upper House regular election 12 registered parties' official and official abbreviated names were extracted, the official names of "Your party", "New Party DAICHI", "People's Life Party", "Green Wind", "Green Party" and "Happiness Realization Party" whose official abbreviated names are "You", "DAICHI", "Life", "Midori (note that 'midori' is the Japanese translation of green), "Green" and "Happiness" respectively could not be identified. Since those unidentifiable parties by party name have lesser power, and also the amount of data collected via Yahoo! Japan real-time search is small, only official names of those parties were used for data gathering. Also, since tweets on Liberal Democratic Party, a majority party, included Democratic Party of Japan, another major party, some procedures were used to distinguish tweets between those two parties.

\subsection{Analysis Method}

Goto (2015) has analyzed a correlation between the total number of postings containing party names on social media during a campaign period and the number of votes each party obtained in the proportional representation system. At the 23rd Upper House regular election held in 2013 R2 is 0.857, and a strong correlation between the number of postings that contained a party name and the party-list votes in the proportional representation system is found. Also, at the 47th Lower House general election in 2014 R2 is 0.880, and Pearson correlation coefficient is 0.938 which is $1 \%$ level and is significant (both sides); thus a strong correlation between the number of tweets containing party name and the total party-list votes in each constituency in the PR system is found. Further, at the 24th Upper House regular election in 2016 R2 is 0.891, and Pearson correlation coefficient is 0.944 which is $1 \%$ level and is significant (both sides); thus a strong correlation between the number of tweets that contained a party name and the total number of party-list votes in each constituency in the proportional representation system is found as well.

In this study, a regression analysis is performed to the above three elections to find the correlation between social media postings and election results. 


\section{ANALYSIS}

In this chapter the past three national elections after the ban on internet election campaign was lifted are analyzed using the methods described in the previous chapter.

\subsection{Analysis of the $23^{\text {rd }}$ Upper House Regular Election}

The terms of office for the Upper House members elected in 2007 expired on July 28, 2013, and 121 seats (73 for constituencies and 48 for the proportional representation system by open list) were included in the election on July 21, 2013. This was the first election where the internet campaign was allowed, and public announcement was made on July 4.

Table 1. Each registered party's total number posted during the 23rd Upper House election

\begin{tabular}{|c|c|c|c|c|c|c|c|c|c|c|c|c|c|c|c|c|c|c|c|}
\hline & Jul. 4 & Jul. 5 & Jul6 & Jul.7 & Jul.8 & Jul. 9 & Jul.10 & Jul.11 & Jul.12 & Jul.13 & Jul. 14 & Jul. 15 & Jul. 16 & Jul.17 & Jul.18 & Jul.19 & Jul.20 & Total & Nr. Of votes \\
\hline YP & 1,586 & 2,311 & 2,102 & 1,803 & 1,891 & 1,534 & 1,791 & 1,661 & 1,767 & 1,586 & 2,709 & 2,132 & 2,628 & 2,079 & 2,171 & 2,031 & 2,115 & 33,897 & $4,221,422$ \\
\hline DPJ & 7,924 & 11,024 & 10,497 & 12,014 & 8,863 & 9,436 & 9,982 & 9,652 & 10,817 & 8,715 & 7,595 & 9,711 & 12,255 & 12,352 & 12,181 & 11,938 & 11,357 & 176,313 & $4,827,158$ \\
\hline NPD & 141 & 2,744 & 844 & 413 & 327 & 220 & 369 & 327 & 1,065 & 427 & 396 & 376 & 710 & 297 & 433 & 353 & 546 & 9,988 & 398,848 \\
\hline SDP & 1,683 & 3,002 & 1,902 & 2,957 & 2,325 & 1,629 & 1,809 & 1,995 & 1,663 & 1,459 & 1,492 & 1,871 & 1,516 & 1,631 & 1,761 & 2,088 & 2,051 & 32,834 & 983,227 \\
\hline PLP & 1,006 & 2,701 & 2,190 & 2,216 & 2,128 & 1,721 & 1,719 & 1,912 & 1,927 & 2,492 & 2,405 & 2,781 & 2,284 & 2,499 & 3,110 & 3,151 & 2,714 & 38,956 & 723,987 \\
\hline GW & 970 & 1,470 & 1,034 & 935 & 899 & 808 & 837 & 849 & 748 & 803 & 1,135 & 1,426 & 1,542 & 1,338 & 1,276 & 1,404 & 1,501 & 18,975 & 319,630 \\
\hline LDP & 9,577 & 24,012 & 33,144 & 25,220 & 19,431 & 17,485 & 16,506 & 14,894 & 15,498 & 15,643 & 15,934 & 18,407 & 18,437 & 22,023 & 30,730 & 28,149 & 30,409 & 355,499 & $14,080,143$ \\
\hline$J C P$ & 1,212 & 3,348 & 3,112 & 3,211 & 2,971 & 2,734 & 2,484 & 2,815 & 2,998 & 2,637 & 2,446 & 2,890 & 3,285 & 3,372 & 3,838 & 4,146 & 4,726 & 52,225 & $4,647,765$ \\
\hline KOM日 & 1,285 & 3,805 & 3,054 & 3,311 & 3,413 & 2,855 & 2,457 & 2,639 & 2,587 & 2,334 & 2,957 & 3,247 & 3,752 & 3,961 & 4,237 & 4,325 & 4,303 & 54,522 & $3,333,142$ \\
\hline GP & 1,144 & 1,839 & 2,720 & 2,010 & 1,496 & 1,695 & 1,733 & 2,580 & 2,405 & 2,591 & 2,509 & 2,931 & 3,647 & 4,075 & 3,578 & 3,556 & 3,985 & 44,494 & 242,460 \\
\hline JRP & 2,845 & 5,463 & 5,144 & 5,463 & 5,786 & 6,919 & 6,263 & 6,220 & 5,044 & 6,791 & 8,591 & 7,096 & 5,538 & 5,897 & 6,242 & 6,177 & 7,023 & 102,502 & $5,191,563$ \\
\hline HRP & 935 & 1,730 & 1,248 & 1,288 & 1,482 & 1,502 & 1,447 & 2,031 & 2,340 & 2,242 & 2,383 & 2,398 & 2,807 & 3,405 & 2,648 & 2,793 & 3,384 & 36,063 & 153,296 \\
\hline
\end{tabular}

Table 1 shows the number of postings containing party names on Twitter and Facebook, (note that the number of postings in this section is the total from Twitter and Facebook), total number of postings and the votes each party received in the proportional representation system between the day of the official announcement and the day before a voting date. A regression analysis 2 was performed with the total number of postings containing a party name as an independent variable and with the total number of votes those parties each obtained as a dependent variable. A regression line is given by $\mathrm{Y}$ (votes gained $)=37.402 \times x($ number of postings $)+279687.511$ with $\mathrm{t}$-ratio $=7.443, \mathrm{p}$-value $=0.000, \mathrm{R} 2=0.874$, and $\mathrm{F}=55.403$. Figure 1 shows a scatter plot. And as Figure 2 of scatter plot standardized residuals shows, standardized residuals is within \pm 2 .

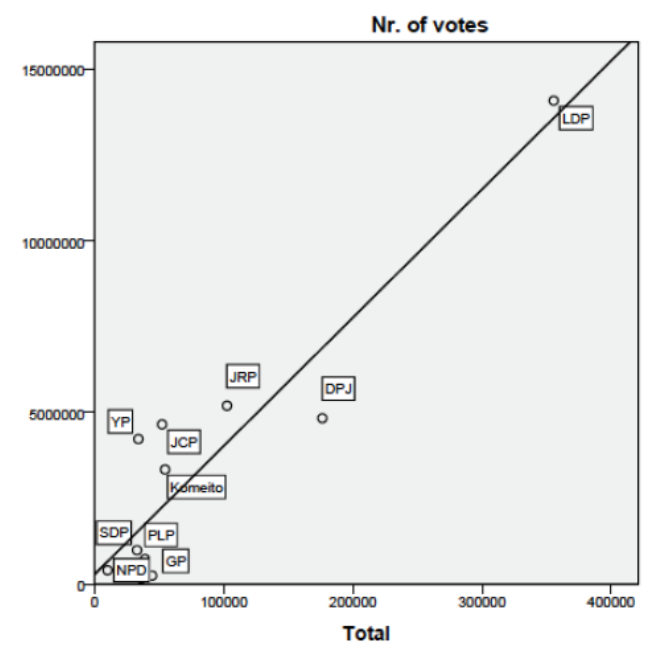

Figure 1. Scatter plot

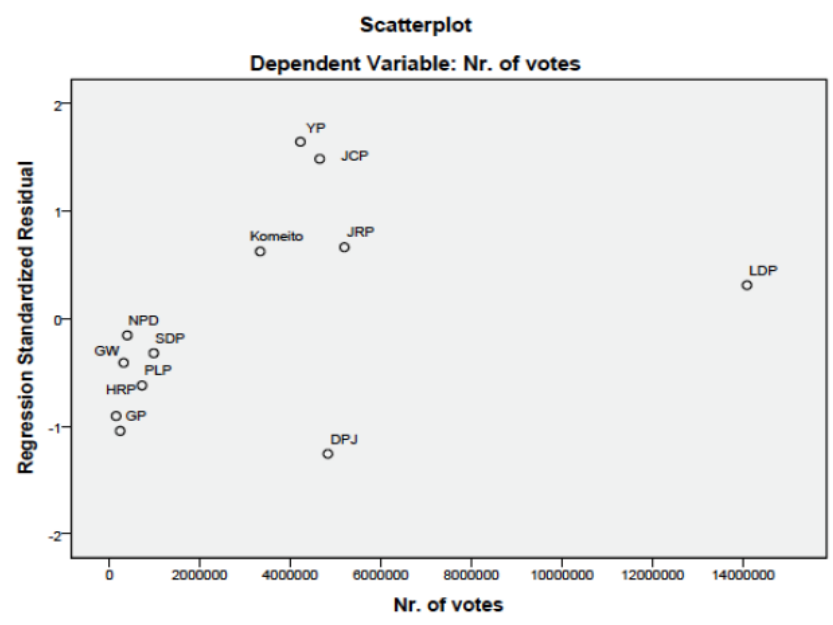

Figure 2. Scatter plot of standardized residuals

${ }^{2}$ SPSS Ver.24 was used. 
A seats prediction can be calculated by multiplying the ratio of the number of postings on each party and 48 seats in the proportional representation, and the comparison with actual election results is made in Figure 3. The prediction errors are 0 for Liberal Democratic Party of Japan, 2 for Democratic Party of Japan, 4 for Komeito, 1 for Japan Restoration Party, and 2 for Japanese Communist Party. Except for Komeito, which relies on organized votes and has a large error, errors are within two seats; therefore, it is suggested that election results predictions in the proportional representation system are correctly made.

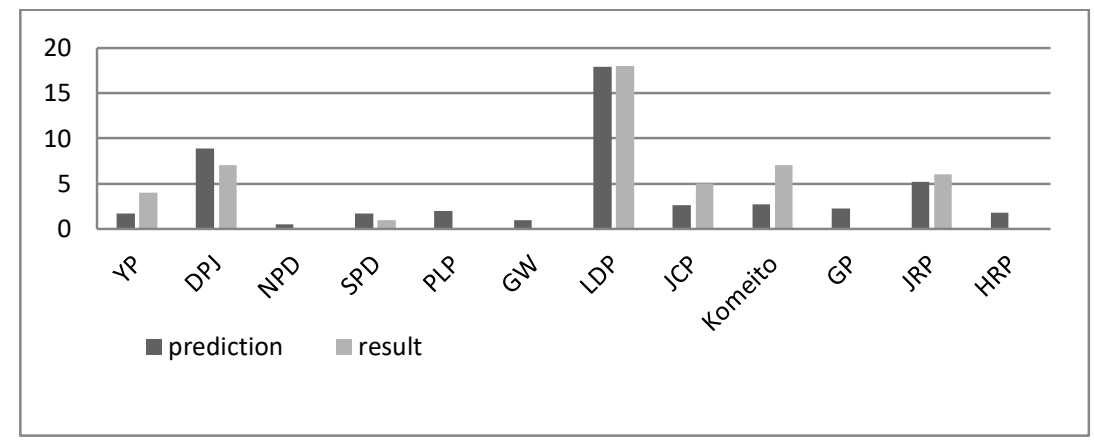

Figure 3. Results predictions in PR system by social media and actual results

\section{$5.247^{\text {th }}$ Lower House General Election}

Due to the dissolution of the Lower House on November 21, 2014, a national election was called for 475 seats (295 for small constituencies and 180 for proportional representation system by fixed list). The election was publicly announced on December 2 and voted on December 14.

The number of tweets containing party name (the number of postings on the 47th Lower House general election is from Twitter only), total number of tweets and total number of votes each party gained in 11 electoral districts (Hokkaido, Tohoku, Kitakanto, Minamikanto, Tokyo, Hokurikusinetsu, Tokai, Kinki, Chugoku, Shikoku, Kyushu) are shown in Table 2. Also Table 3 shows the same items after the "emotion analysis" through Yahoo! Japan real-time search was made.

Table 2. Each registered party's total number posted during the 47th Lower House election

\begin{tabular}{|c|c|c|c|c|c|c|c|c|c|c|c|c|c|c|}
\hline & Dec. 2 & Dec. 3 & Dec. 4 & Dec. 5 & Dec. 6 & Dec. 7 & Dec. 8 & Dec. 9 & Dec. 10 & Dec. 11 & Dec. 12 & Dec. 13 & Total & Votes \\
\hline LDP & 28,543 & 24,607 & 40,095 & 32,825 & 34,458 & 35,868 & 39,460 & 37,649 & 37,557 & 37,335 & 41,140 & 55,762 & 445,299 & $17,658,916$ \\
\hline NRP & 363 & 237 & 170 & 171 & 116 & 159 & 96 & 95 & 78 & 75 & 101 & 202 & 1,863 & 16,597 \\
\hline DPJ & 19,958 & 15,786 & 21,535 & 17,870 & 18,922 & 21,622 & 21,734 & 21,862 & 24,073 & 22,613 & 21,637 & 25,699 & 253,311 & $9,775,991$ \\
\hline KOME & 8,801 & 7,367 & 9,006 & 9,845 & 9,577 & 8,589 & 11,713 & 10,662 & 10,493 & 8,853 & 8,417 & 11,726 & 115,049 & $7,314,236$ \\
\hline SPD & 3,562 & 3,001 & 2,891 & 2,497 & 2,608 & 2,771 & 2,772 & 3,887 & 3,872 & 3,733 & 3,981 & 5,609 & 41,184 & $1,314,441$ \\
\hline JRP & 5,760 & 5,638 & 6,777 & 5,301 & 5,937 & 6,743 & 7,159 & 6,761 & 7,417 & 6,647 & 6,633 & 10,241 & 81,014 & $8,382,699$ \\
\hline HRP & 1,376 & 130 & 867 & 929 & 904 & 956 & 967 & 975 & 1,014 & 996 & 1,222 & 1,417 & 11,753 & 259,060 \\
\hline PLP & 1,612 & 1,311 & 1,604 & 1,557 & 1,996 & 1,711 & 2,263 & 2,226 & 2,297 & 2,374 & 2,200 & 2,928 & 24,079 & $1,028,721$ \\
\hline JCP & 12,408 & 10,663 & 13,568 & 11,589 & 12,508 & 14,572 & 14,388 & 19,064 & 17,317 & 22,283 & 20,205 & 23,997 & 192,562 & $6,062,962$ \\
\hline
\end{tabular}

Table 3. Each registered party's total number posted excluding negative postings during the 47th Lower House election

\begin{tabular}{|l|r|r|r|r|r|r|r|r|r|r|r|r|r|r|}
\hline & Dec. 2 & Dec. 3 & Dec. 4 & Dec. 5 & Dec. 6 & Dec. 7 & Dec. 8 & Dec. 9 & Dec. 10 & Dec. 11 & Dec. 12 & Dec. 13 & Total & Votes \\
\hline LDP & 12,273 & 11,565 & 19,246 & 14,771 & 15,506 & 15,782 & 17,362 & 16,189 & 16,901 & 16,801 & 18,924 & 24,535 & 199,855 & $17,658,906$ \\
\hline NRP & 225 & 142 & 136 & 125 & 86 & 121 & 65 & 76 & 76 & 51 & 68 & 127 & 1,298 & 16,597 \\
\hline DPJ & 8,981 & 8,051 & 11,629 & 8,399 & 9,083 & 10,811 & 10,650 & 10,712 & 12,518 & 12,211 & 11,684 & 12,850 & 127,579 & $9,775,991$ \\
\hline KOME & 4,753 & 3,978 & 5,043 & 5,513 & 5,842 & 4,896 & 7,613 & 6,717 & 6,611 & 5,046 & 4,882 & 6,449 & 67,343 & $7,314,236$ \\
\hline SPD & 2,030 & 1,681 & 1,677 & 1,498 & 1,591 & 1,552 & 1,552 & 2,332 & 2,478 & 2,314 & 2,468 & 3,702 & 24,875 & $1,314,441$ \\
\hline JRP & 3,110 & 3,101 & 3,863 & 2,863 & 3,325 & 3,844 & 3,937 & 3,516 & 4,228 & 3,589 & 3,847 & 5,530 & 44,753 & $8,382,699$ \\
\hline HRP & 867 & 87 & 555 & 632 & 579 & 669 & 600 & 624 & 659 & 657 & 880 & 1,006 & 7,815 & 259,060 \\
\hline PLP & 1,225 & 1,009 & 1,283 & 1,199 & 1,617 & 1,317 & 1,833 & 1,759 & 1,907 & 1,828 & 1,738 & 2,313 & 19,028 & $1,028,721$ \\
\hline JCP & 5,584 & 5,012 & 6,648 & 5,679 & 6,004 & 7,286 & 6,906 & 9,341 & 8,659 & 10,919 & 10,709 & 11,999 & 94,746 & $6,062,962$ \\
\hline
\end{tabular}


A regression analysis was performed with the total number of postings containing a party name as an independent variable and with the total number of votes those parties each obtained as a dependent variable.

A regression line is given by $\mathrm{Y}$ (votes gained) $=89.935 \times \mathrm{x}$ (number of postings) +279959.002 with $\mathrm{t}$-ratio $=7.555$, $\mathrm{p}$-value $=0.000, \mathrm{R}^{2}=0.880$, and $\mathrm{F}=55.403$. Figure 4 shows a scatter plot. And as Figure 5 of scatter plot standardized residuals shows, standardized residuals is within \pm 2 .

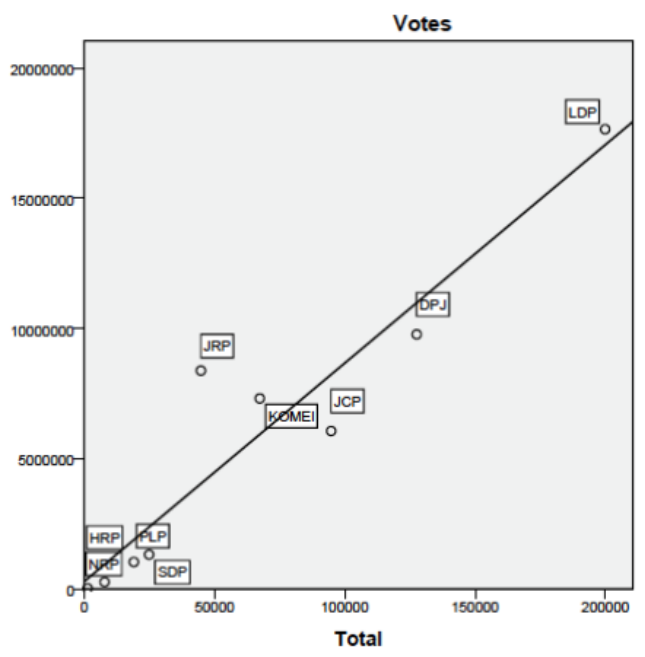

Figure 4. Scatter plot

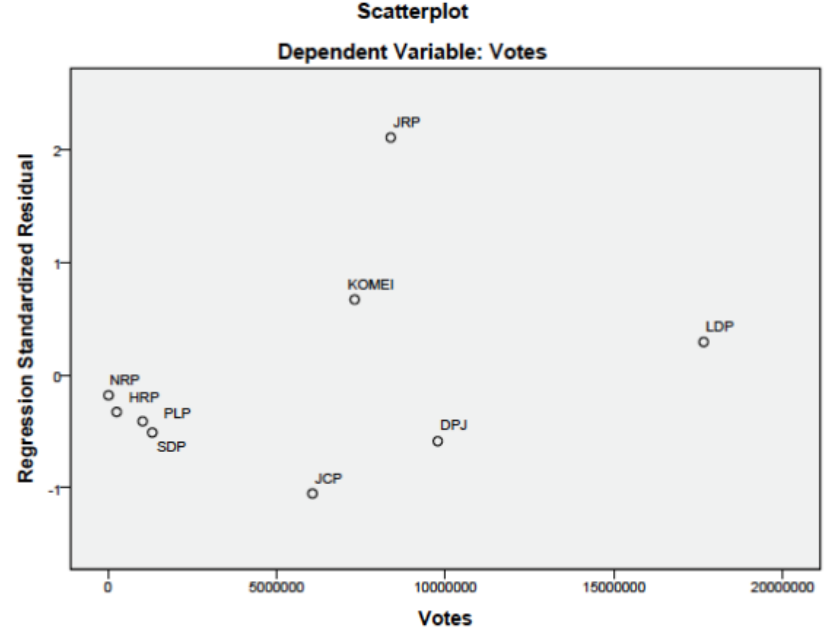

Figure 5. Scatter plot of standardized residuals

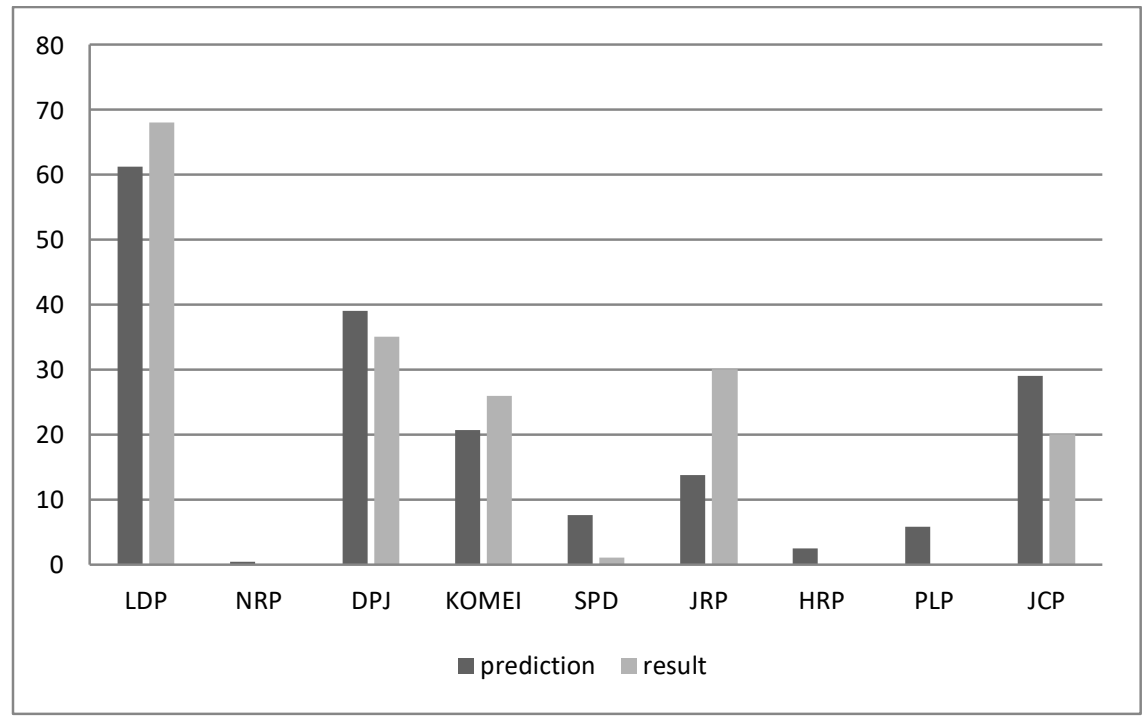

Figure 6. Results predictions in PR System by social media and actual results

A seats prediction can be calculated by multiplying the ratio of the number of postings on each party and 180 seats in proportional representation, and the comparison with actual election results are made in Figure 6. The prediction errors were 7 for Liberal Democratic Party of Japan, 4 for Democratic Party of Japan, 5 for Komeito, 7 for Japan Restoration Party, and 9 for Japanese Communist Party. Those errors are considered to be caused by the complicated Lower House electoral system, under which the number of seats in the Lower House is over three times the number of seats in the Upper House, candidates win by sekihairitsu (best loser calculation), some parties do not list candidates in the proportional representation system in some of the 11 constituencies, etc. 


\section{$5.324^{\text {th }}$ Upper House Regular Election}

On July 25, 2016, the terms of office for the half of the Upper House members elected in 2013 expired, and a national election was called for 121 seats ( 73 for constituencies and 48 for proportional representation system by open list). The election was publicly announced on June 22 and voted on July 10.

Table 4. Each registered party's total number posted during the $24^{\text {th }}$ Upper House election

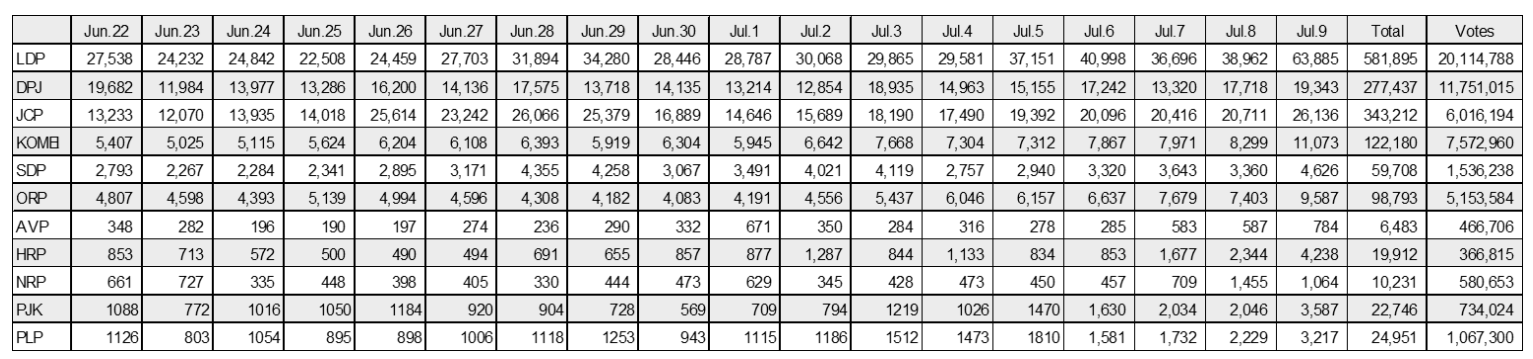

The number of tweets on each party posted (the number of postings on the 24th Upper House regular election is from Twitter only), total number of tweets and total number of votes each party gained during the campaign (between the day of public announcement and the day before the voting) are shown in Table 4.

A regression analysis was performed with the total number of postings containing a party name as an independent variable and with the total number of votes those parties each obtained as a dependent variable. A regression line is given by $Y$ (votes gained) $=89.935 \times x$ (number of postings) +27.775 with t-ratio $=8.565$, $\mathrm{p}$-value $=0.000, \mathrm{R} 2=0.891$, and $\mathrm{F}=73.362$. Figure 7 shows a scatter plot. And as Figure 8 of scatter plot standardized residuals shows, standardized residuals is within \pm 2 .

A seats prediction can be calculated by multiplying the ratio of the number of postings on each party and 48 seats in proportional representation, and the comparison with actual election results are made in Figure 9. The prediction error is 1 for Liberal Democratic Party of Japan, but prediction errors widen because, in this election, the same individuals tweeted the same content many times.

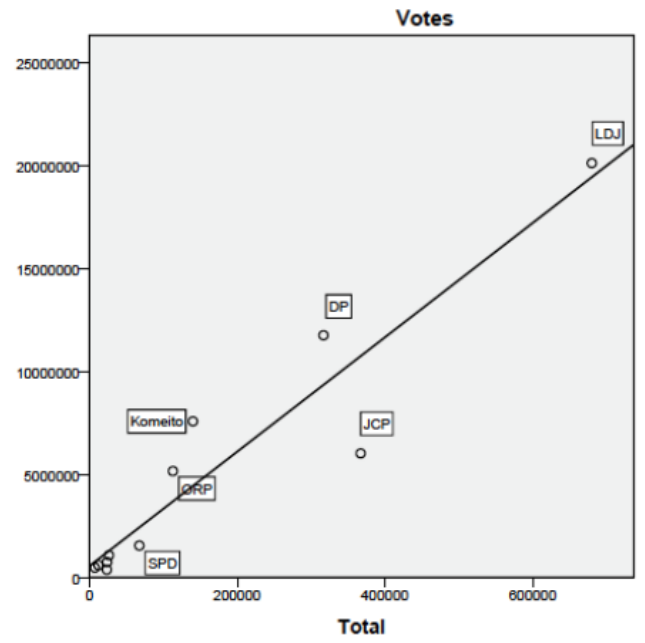

Figure 7. Scatter plot

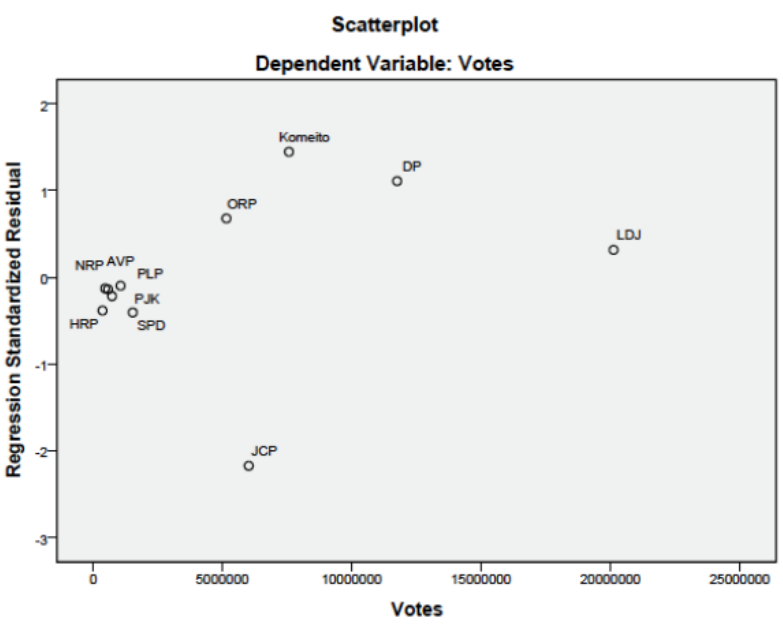

Figure 8. Scatter plot of standardized residuals 


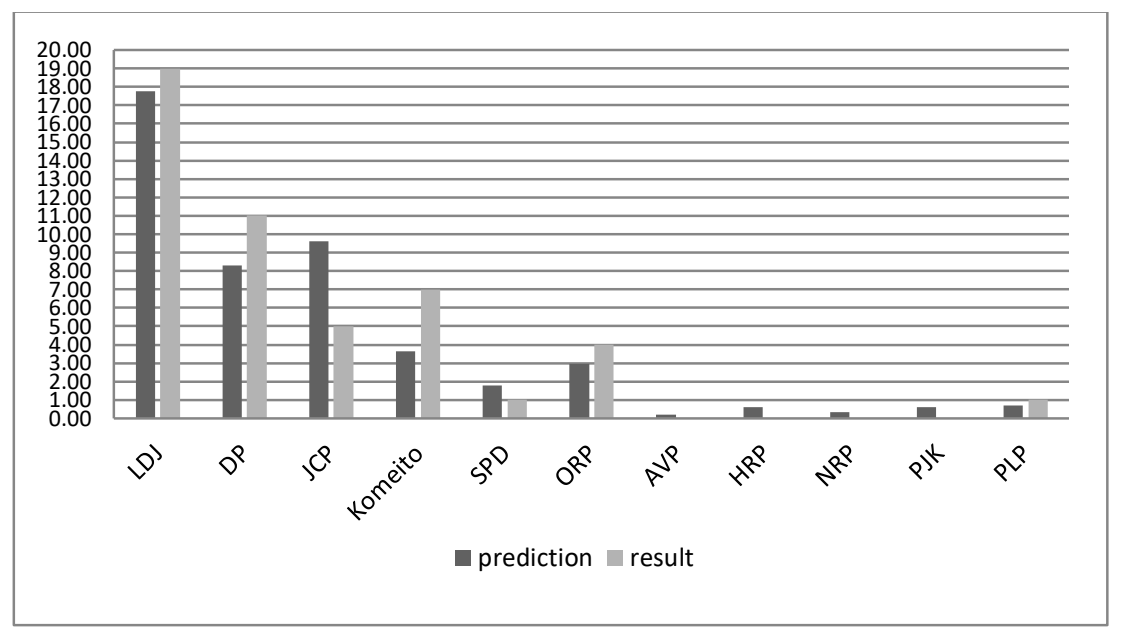

Figure 9. Results predictions in PR system by social media and actual results

\section{CONCLUSION}

In this research, it is found that results predictions of Japan's national elections using social media is possible in a more frequent manner at lower cost with higher accuracy compared to the conventional research through RDD. As described in Chapter 3, Literature Review, although it is difficult to make predictions on parties or candidates in small-constituency districts or who rely on organized votes, election results predictions using social listening in the proportional representation system are effective. Especially the predictions for the proportional representation system in Upper House elections, which is voted nation-wide, were more precise than those in Lower House elections in which the nation is divided into 11 districts. In addition, adding variables such as the number of party members would make more precise predictions possible than through the conventional methods.

In the era of the "Information Explosion", social listening or big data such as IoT, or a combination of both are essential tools for not only business management but also for problem solving or prediction-making.

\section{REFERENCES}

Goto, Hisaki 2015 A study of Elections using Social Media and the Internet Journal of Japan Society for Information and Management, 35 (4), 34-42(Japanese)

Jungherr, Andreas. et al 2012 Why the Pirate Party Won the German Election of 2009 or The Trouble with Predictions Social Science Computer Review 30 (2), 229-234

Nasuno, Kaoru. et al 2013 Predicting Japanese General Election in 2013 with Twitter: Considering Diffusion of Candidates' Tweets IECE Technical Report. NLC, Natural language understanding and models of communication, 11113 (338), Japan, 25-28

Nasuno, Kaoru. et al 2014 Considering Diffusion of Candidates' Tweets The 28th Annual Conference of the Japanese Society for Artificial Intelligence, Japan, 1-4 (Japanese)

Yoshimi, Kenji 2016 Usage Tendencies of Social Media by Each Political Party during Election Campaign — A Study on Twitter Use in the 47th General Election - Socio Informatics, 4 (3), Japan, 16-29 (Japanese)

Tumasjan, Andranik. et al 2010 Predicting Election with Twitter: What 140 Characters Reveal about Political Sentiment Proceedings of the Fourth International AAAI Conference on Weblogs and Social Media, 178-185 